\title{
The Political Knowledge of University Students (A Comparative Study between Jordan and Libya)
}

\author{
Alfeetouri Salih Mohammed Alsati ${ }^{1} \&$ Al-Sayed Abd ulmutallab Ghanem ${ }^{2}$ \\ ${ }^{1}$ Faculty of Economy and Political Science, Bani Walid University, Libya \\ ${ }^{2}$ Faculty of Economy and Political Science, Cairo University, Cairo, Egypt \\ Correspondence: Alfeetouri Salih Mohammed Alsati, Faculty of Economy and Political Science, Bani Walid \\ University. E-mail: alsatialsati@gmail.com
}

\author{
Received: August 27, $2017 \quad$ Accepted: September 15, $2017 \quad$ Online Published: October 28, 2017 \\ doi:10.5539/ass.v13n11p13 URL: https://doi.org/10.5539/ass.v13n11p13
}

\begin{abstract}
The current research aims at identifying and measuring the political knowledge of the students of the two universities of Al- Balqaa in Jordan and Omar Al- Mokhtar in Libya. The two communities are almost similar in terms of the social formation, Arab customs and traditions, the Bedouin values, the difference in the institutional age and the political stability.

The study attempts to measure and compare the political knowledge in the communities of the two universities using the descriptive and comparative analytical method. The study uses a 400 random questionnaire of 30 paragraphs to measure eight indicators divided into internal and external political knowledge, and other aspects of knowledge: general political knowledge, knowledge of the political institutions and leaders, the political interest, the geographical and historical knowledge, and knowledge of the methods of exercising the political process. The study also attempts to identifying the most important sources and the role of the university in university students' political knowledge.

The results show that the level of the political knowledge is medium while its level in the sample of the Jordanian students is high. According to the samples, the internal political knowledge is more than the external knowledge with a lack of interest in the political matters. The samples do not consider the political matters as their priorities. The political knowledge as a whole needs to much effort to be exerted to confront the current circumstances. The variables of the place of resident, age and the educational level make big difference in the political knowledge. In contrast, the level of the parental education does not create big differences.
\end{abstract}

Keywords: Political knowledge, legal knowledge, political process, political systems, Jordan, Libya

\section{Introduction}

The knowledge increase and its sources vary as a result of the tremendous developments in the field of technology. The intellectual, scientific, cultural and social achievements multiply. As a result, it becomes a close relationship between knowledge and the scientific and technological revolution. The cognitive outcome of any community becomes the power that shapes its present and safeguards its future (Al- Shara, 2014). The political knowledge means the citizen's cognition of his political right and duties, the events surrounding him, to what extent he perceives his surrounding reality as a whole truth (Muawwad, 1983). It is the accumulated cultural aspects that is related to the political matters for persons that increases by the formation of awareness and the interest in political activities (Al- Abdaly, 2007), the cognition of political issues and making opinion about them. Also, it is the first dimension of the political cultural aspects (Gabriel, 1990). The political cognition is also considered one of the aspects that follow awareness. The accumulated knowledge with other factors leads to the formation of trends ${ }^{1}$ that contribute to forming the values (Siddiq, 2012) and identifying the political knowledge. The democratic system increases the active political participation and achieves equality and social justice (Al-Tabib, 2001). The good political system asks the citizen to be aware of the appropriate knowledge and skills for participation and to gather its most important fruits, that is, the political stability (Galston, 1991). Because most of the studies of the political systems are based on comparison, we have to make the study of the political knowledge of university students a comparative study between the level of political knowledge of university

1 - Most of studies defined the formation of trends by three aspects: passionate, cognitive and behavioral. 
students in two close communities in terms of values, customs and traditions. The difference between the two communities that one of them is politically stable and has old democratic institutions and the other is under a totalitarian system and instable (Zawati, 2016). The current study attempts to measure the level of the political knowledge of the Jordanian and Libyan university students to identify the difference and define the level of the political knowledge between this section of community.

The variables of the political stability, the kind and institutions of the political systems of the two countries are different (Howk, 2008). Therefore, the current study aims at explaining the effects of the independent variables on the political knowledge indicators for the category of students. The research's problematic focuses on considering the political knowledge the first stage of the stages of participation. The political knowledge ranges from the political interest to voting and finally the political request (Dimitrova \& others, 2014). The political knowledge and its different dimensions are considered from the basic factors to achieve the active political participation (Al- Nabolsi, 2010) especially the latter is regarded as from the important problematic that face the communities in paving their way towards the development (Almond, 1963).

The current study employs a descriptive analytical method that describes the phenomenon in general, and then analyzes the mathematical results for detecting. The researcher expects clear results that the political knowledge of university students in Jordan is wider due to the long period of time of the political and institutional stability. Additionally, the researcher assumes that the level of the internal political knowledge is higher than the external political knowledge of students of the two universities. There is a positive effect for the parental educational level on the level of the political knowledge of children. For the results of the sample, the researcher expects a positive relationship between the age and the political knowledge. The study derives its data from a sample of Jordanian and Libyan university students represented in a sample of Balqaa University in the Jordanian Kingdom $^{2}$ and Omar Al- Mokhtar University in Libya ${ }^{3}$ in spring $2015-2016$. The sample consists of 400 persons whose age ranging from 18-30 years. Randomly, the sample is chosen. To verify the assumptions, the study is divided into two topics.

\section{The First Topic: The Nature and Measurement of the Political Knowledge}

To identify and measure the political knowledge, it is divided into a number of indicators for the political knowledge. It includes internal political knowledge that is interested in the internal political matter, and external political knowledge that is interested in the regional and international political knowledge but not the local level. It is interested in the historical knowledge to measure the political events in the past and the knowledge of the political institutions to measure to what extent the student is aware of the political institutions. It includes also the student's knowledge of the political characters to measure the knowledge which is in the student's mind about the names of the prime ministers and the political leaders. The indicators of the political knowledge measures the interest in the political subjects and the ability to make an opinion about these topics for the purpose of measuring the interests of the student in the political aspects, following their events and making a point of view about them. It also examines to what extent the students are aware of the most important national and international political events. In addition, the indicators measure the geographical knowledge, that is, to measure information about the political geography, such as the names and strategic importance of the countries, capitals, borders and areas, gulfs, seas and straits. They measure the most important aspects of exercising the political process and identify the most significant sources of the student's political knowledge that have the priority so that the political system can focus on. It is a comparative study between two different environments, but they are socially close, in terms of political stability. They also measure the political knowledge of all members of the sample. Therefore, the indicators of these aspects depend on the phrases that measure all their cognitive aspects. By the use of hallmarks for every level and description of the indicator of measuring knowledge and all different sub-indicators according to independent variables, such as the age, the place of residence, the effect of the parental education and the grade.

\section{The Sample of the Research and its Tools}

The study discusses the university stage. According to the results of the sample's description, it shows that:

A- According to the age, $48 \%$ of the sample of Al-Balqaa University are from $20-24$ years, $52 \%$ for the category that is older than 25 years. While the sample of Omar Al-Mokhtar University includes students

2- To know more about Al- Balqaa University, see http:// www.bau.deu.jo. The last checking of the website was on 22nd July, 2017.

3- Omar Al- Mokhtar University (the headquarter) in the city of Al- Baidaa in the east of Libya. 
who are 20 years old and younger by $42.5 \%$, from $21-22$ years old by $53.11 \%$ and older than 25 years by $4.39 \%$.

B- It is statistically tackled by using the program of the Statistical Package for Social Sciences (SPSS) to find the following statistics: mathematical averages, standard deviations, Spearman's coefficient of correlation to measure to what degree the correlation between the hierarchical variables, Cronbach's Alpha which is a measure used to assess reliability ${ }^{5}$. The rate of honesty is $0.834 \%{ }^{6}$. Questionnaires are examined by specialized professors in this field. Their notices are taken into consideration ${ }^{7}$. The questionnaire is prepared to include 30 questions which are classified two sections: data including the place of residence, major, the family's income as independent variables. Another section includes questions as a measure of the political knowledge and its various aspects using marks to measure every question.

\section{The Second Topic: Results and Discussion}

4.1 According to the sample, the results show that the level of the political knowledge of university students is ranged from medium to fully low. There are differences in the political knowledge for the advantage of the sample of the Jordanian students. For the Libyan students, the internal knowledge, the knowledge of the political institutions and general information are lower than the Jordanian students. Whereas the results show a high level in the foreign political knowledge for the Libyan students as it is laid down in the following table:

Table 1. The percentage of every dimension of the political knowledge of the study's sample

\begin{tabular}{cccccc}
\hline \multirow{2}{*}{ The kind of political knowledge } & \multicolumn{2}{c}{ The University of Balqaa in Jordan } & \multicolumn{2}{c}{ The University of Omar Al- Mokhtar in Libya } \\
\cline { 3 - 5 } & percentage & degree & percentage & degree \\
\hline 1 & Internal political knowledge & $39 \%$ & Medium & $35 \%$ & Medium \\
2 & Foreign political knowledge & $36 \%$ & Low & $41 \%$ & Medium \\
3 & Knowledge of political institutions & $48 \%$ & Medium & $35 \%$ & Medium \\
4 & Political knowledge in general & $40 \%$ & Medium & $34.5 \%$ & low \\
\hline
\end{tabular}

From the table, it is clear that the degree of knowledge of political aspects is medium in the whole sample. The result is attributed to the fact that students are not interested in political events and issues. For the sample of Balqaa University, the results show that the high percentage of the knowledge of political concepts and terms is $80 \%$. It is attributed to the long period when the students lived exercising political democracy (Al-Mashaqia, 2015) in contrast to the Libyan student who is politically destabilized as a result of different forms of systems applied to him (Khalil, 2003) as they are laid down in the level of the political concepts of the Libyan University students by $48 \%$.

As for following up the political news, the results of the sample show that the majority does not follow the political news and they are interested in sporty, cultural and religious news. The order of the political programs is the fourth in terms of the political interest. The results of the Libyan University students show a high percentage of persons who are not interested in politics. The results show that $70.1 \%$ do not interested in politics and its subjects. The results also show that $16.2 \%$ give their priority to the political matters. While $6.5 \%$ consider the political issues at the second order. The current results are somewhat in line with the result of Al- Hariri's study. The order of the interest in the political topics is the third between the priorities of the matters which are the most to be followed (Al- Hariri, 2011). The current results are in conformity with the results of Al-Awamla and Al-Shenikat's study that refers to the level of a moderate political awareness of the applicable university of Al-Balqaa students (Al- Awalma and Al- Shenikat, 2012) and the study conducted by Al-Zyadat and Qatawi that refers to a roughly medium level of awareness by $66.3 \%$ for the teachers of the social studies (Al- Zaydat \& Qatawi, 2010). Also, the results are close to the results of Al-Masry's study (Al - Masri, 2007) that refers to a roughly medium level of the political awareness for its members (Al - Shara, 2014). The results of the study

4 The age from 25 and older is the category of the post - graduate students.

5 An exploratory study was conducted on a 15 - person sample to ensure that the questions of the questionnaire are fixed and clear.

6 Cronbach's alpha is a measure used to assess the honesty of the questionnaire. The questionnaire is more honest, when the result is higher than $(0.6 \%)$.

7 The arbitrators of the questionnaire: Political science: Abdel Ghaffar Rashad, Al -sayed Ghanim, Cairo University, Zahi AlMaghrabi, the university of Qar Younes, Mohamed Deryaq, the university of Sirte, Ashraf Bin Lama, the university of Bani Walid in Libya. 
show the most part of the students' concentration on their courses and curriculum which are almost away from the political topics especially in the majors of the applicable sciences which most of parents seek to direct their sons and daughters to study (Nour Eddin, Mubarka, 2016). It shows that the university performs somewhat its role and it decreases its role in distributing the political awareness (Jacabson, 2001). For Libya, in the previous period of time, most the Libyan universities cancelled the sections of the political science and decreased its role. The independent faculties of political science were changed to be sub-sections (the Libyan Organization for politics and Strategies, 2016).

There are differences between the two samples in terms of the high level of the external knowledge among the Libyan students. It refers to the effect of the tools of transferring the culture to the external knowledge which is usually made by other countries and foreign institutions that aim at transferring their cultures to other communities. They try to fill the gap and shortage in knowledge in a way that conforms to their ideologies through the different ways of transferring the cultures (Al- Tabib, Khaira, 2012). They take opportunity of the lack of the censor institutions in the community and change the world into one village that can be filled with other cultures coming from societies that seek to distribute their cultures (Abu Ali, 2014).

Moreover, the results of analysis show that the level of the international political knowledge is medium according to the two samples of Jordan and Libya. The results show that the percentage of the internal knowledge of the Jordanian students is $39 \%$ while it is $35 \%$ in the sample of the Libyan students. It is noted a close percentage for the internal political knowledge. It refers to a close level of the interest in the political matters and the tools of transferring knowledge and employing a somewhat similar method.

\subsection{The Historical Knowledge}

The historical knowledge means the political aspects in the dates, decisions, international and regional treaties, the dates of the battles of Jihad and liberation, the narration of previous historical events and situations from the political point of view. The results of the analysis show that the level of the historical knowledge for the students of the Jordanian University of Al- Balqaa is medium by $55.6 \%$. There is an increase in the level of knowledge about the constitutional articles by $70 \%$, about the regional organizations and the date when Jordan joined to, such as the Arab League and the United Nations by $75 \%$. For the Libyan students, the results show that the level of the historical knowledge is medium by $49.7 \%$. The level of knowledge about the Libyan constitutional articles is low. For the samples, the right answers are by $38.2 \%$ in relation to some questions about the constitution. It is attributed to the fact that the constitution was suspended from 1969 to 2012 (Capasso, 2013). The right answers were also about the totalitarian rule during this period of time that followed a certain ideological context. Whereas the percentage of the right answers about the question of the date of the independence of Libya is up to $39.2 \%$. However, there was a kind of confusion about the date of declaring its independence in the United Nations and the real date of its independence. The results refer to the fact that the majority do not know the dates when Libya joined the regional and international organizations. The percentage of the students who do not know when Libya joined the Arab League is $14.1 \%$ whereas the percentage of who were aware of the dates of occupation, liberation, national days is high by $70.4 \%$ because most of the students were aware of these items. It may be attributed to the fact that the educational curriculum succeeded in informing the historical information and early focusing on the battles of Jihad and days of independence in the educational curricula.

\subsection{The Knowledge of Characters and Political Leaders}

It means to what extent the student is aware of the different characters and leaders, such as the leaders of the parties and Jihad, the political leaders. The results of the analysis refer that the level of cognizance of the characters and political leaders for the students of Al-Balqaa University is high by $71 \%$. The students were aware of the names of the Jordanian prime minister and easily of the names of the most important three political parties. They mentioned the most important historical events and identified their dates. It is noted that the level of the Libyan students about his knowledge of the characters and the political and historical leaders is low. The results show that the percentage of their knowledge is $54 \%$. The results also say the level of the sample's knowledge about the speaker of the House of the Representatives is high by $70 \%$. The level decreased to $16.3 \%$ for the level of knowing the name of the prime minister. The results are laid down in the following table:

The results show that the percentage of knowing the full name of the prime minister is low because of the effect of the events and talk show programs accompanied with the formation of the proposed government of reconciliation in Sokhairat in Morocco during distributing the questionnaires. The percentage of knowing the characters and liberation leaders is high. The percentage of the students who know Omar Al-Mukhtar is 98.8\%. For identifying the belonging to the political leader, the sample could define the block to which the previous prime minster (Ali Zaidan) belonged by a low percentage of $24.9 \%$. The students were confused and could not 
differentiate between some points as a result of the new life of the parties in Libya at first. Second, the parties were accredited only in the elections of the national conferences (Staw, 2013) whereas they were excluded in the elections of the House of the Representatives (the Parliament). Therefore, it is noted that the knowledge of politics and the names to which are related is limited. It is clear the effect of the temporal factor on the sample as a result of the emergence of the democratic political institutions.

Table 2 shows the results of the indicators of the cognizance of characters and political leaders according to the sample

\begin{tabular}{lllll}
\hline The indicator & Category & Marks & level & percentage \\
\hline The knowledge of the characters and the political leaders & The Libyan University & Zero ---1 & Low & $54 \%$ \\
& & $1.1---2.1$ & Medium & \\
& The Jordanian University & $2.2----3$ & good & $71 \%$ \\
\hline
\end{tabular}

\subsection{The Interest in the Political Topics and the Ability to Form a Decision about them}

It is related to the political interest, the ability to analyze the political phenomena, making decisions and proposals, and taking attitudes towards them. The results show approximation between the students of the two samples in terms of their interest in political issues and the trial to analyze the political events in general. For the sample of the students of Al-Balqaa University, the level is slightly high. It is shown that the level of the interest of the students of the universities in the political topics is medium. For the Jordanian sample, the percentage is $67.5 \%$ whereas the percentage of the Libyan sample is $60.4 \%$. The students are aware of what the meaning of politics is by $60 \%$ for the Jordanian sample (Al- Momani, 2010) whereas the percentage is $58 \%$ for the Libyan sample. $40.4 \%$ of the sample chooses other choices. It is in line with the study conducted by Shmis which confirms that the interest in and focus on the social and scientific aspects is more the focus on the political aspects for the Arab families (Shmis, 1996). Also, the results show that $47.7 \%$ of the sample know to whom the previous government belongs.

The results show that the students in general do not give their priorities to the political matters. The results show that $18 \%$ of the Jordanian students and $16.2 \%$ only of the Libyan students give priorities to the political subjects. $6.5 \%$ of the students consider the political matter at the second priority. Most of students of the Jordanian sample by $25 \%$ give the political interest to the fourth priority and the political interest to the Libyan students at the fifth priority by $20.1 \%$. A number of the sample's students refused to determine their priorities in terms of the political interest. The percentage of the Jordanian students who avoid answering is $14.3 \%$ and $23 \%$ from the Libyan sample. In previous studies, the results show that the political interest of the Libyan students is at the third priority (Al- Hariri, 2011).

\subsection{The Knowledge of the Political Institutions:}

It means to what extent the knowledge of the students of the political institutions and entities, such as the political parties, the institutions of the civilian community, the unions and associations of students, is. The results refer to the fact that the level of the cognition of the political institutions is medium for the two categories. It is shown that the Jordanian University students are aware of the political institutions by $65 \%$. The results of analysis show that the cognition of the political institutions for the Libyan University students is low by $48.4 \%$.

By a higher percentage, the Jordanian students were aware of the most important three Jordanian political parties by $70 \%$. The knowledge of the Libyan students is by $21 \% .27 \%$ of the students know the name of two parties. $57 \%$ know the name of one party of the participating parties in the last elections. There are differences between the two communities of Jordan and Libya in terms of the old and recent institutions, parties and the whole election process (Center of Cater for Democracy, 2012). In the Libyan case, the parties and their activities are recent because it emerged only in the six previous years. It led to confusion for the Libyan students between the names of the political parties and the emergence of some of other trends (The Team of the European Union, 2012). The results show that the student's awareness of the targets of the student unions is high by $45 \%$ for the sample of Al-Balqaa University and by $39.7 \%$ for the Libyan sample.

\subsection{Geographical Knowledge}

It means the knowledge and experiences in relation to geography, such as the political borders of the countries and continents, the neighboring countries, seas and gulfs and their importance, the areas of countries and their strategic importance. The results show that the level of geographical knowledge for the Jordanian students is high by $70 \%$. Most of the sample's persons know the Jordanian borders by $65 \%$. Most of the sample succeeded in determining Jordan's area, capital and cities. 
The results show that the level of geographical knowledge for the Libyan students is low by $58.2 \%$. It is shown that $23.1 \%$ of the Libyan students know the area of Libya. Other chose the second choice by $30 \%$ which is the Libyan area before the decision of the international court of justice that Aouzou ${ }^{8}$ sector is subject to Chad is issued (Moussa, 2017). It indicates that the level of the international following of the students for decisions is low. The results show that the level of information is low in relation to the number of population by making three Libyan cities in order according to the number of population. There is a question including five questions. Therefore, the sample is requested to put the five cities in order according to people density. $21.1 \%$ of the sample can make the most populated two cities in order. Some of sample's members can put three cities in order by $3.6 \%$ whereas it is an obvious increase in the sample's answers related to the big cities because the majority knows the political and economic capital of the state by $88.1 \%$.

\subsection{Knowledge of the Names and Methods of Exercising the Political Process:}

It means to what extent the student knows and understands some of the political terms such as voting, objection, elections, the peaceful ways of the students for political expression, political objection and the priority that the student gives to these methods in terms of their significance. The results show that the sample's knowledge of these methods is medium. They show that the level of knowledge of these methods for the Jordanian students is medium by $60 \%$. Also, it is medium for the Libyan students by $55.2 \%$.

In relation to the names of the political processes, there is a question about the process according to which the members of the national conference and the members of the House of the Representatives are chosen. The students who know the right answer are by $70 \%$ for Jordanian students and by $41.3 \%$ for the Libyan students. The students can differentiate between some of political terms (Power, peace, accord and treaty) by $66 \%$ for the Jordanian students and by $63.1 \%$ for the Libyan students.

\subsection{The Most Important Sources of Political Knowledge for the Students}

The date of study shows that the internet and media are at the top of the sources of the political knowledge. $62.4 \%$ of the Jordanian students and $44.4 \%$ of the Libyan students resort to the internet to get information and knowledge to reduce the shortage of the political knowledge. Therefore, the current study is in conformity with a previous study that considered the internet one of the most important sources of political knowledge by $45 \%$ (Miloud, 2013), followed by the university and the curriculum by $34.2 \%$ for the Libyan youth. The Jordanian youth see the educational curriculum contribute by $37 \%$ in the political knowledge. Therefore, the role of friends is by $6.2 \%$.

\section{The Third Topic: the Effect of the Independent Variables on the Level of the Political Knowledge for the Sample}

\subsection{The variable of age}

The results of the analysis show that there is an increase in the political knowledge in relation to the old age of the sample of the Jordanian university students. It refers to a direct relationship between the age and the level of the political knowledge. It is shown that the level of the political knowledge of the first stages of the university academic years by $47.5 \%$ whereas it is at the last stages of the academic years by $52.5 \%$. This result is attributed to an increase in the awareness and general and political knowledge developing with the development of the age. There is a similarity to a large degree between political information and knowledge for the sample in similar academic grades and different majors. It is attributed to the fact that the university students study in the same faculty and attend similar conferences in a large degree in faculties and schools (Haron, 2010).

For the Libyan sample, the results are contrary to the results of the previous Jordanian sample. The analysis shows that there is a close relationship between the level of the political knowledge of the Libyan sample and their age especially younger students between 19 and 22 years old. It is shown that the level of the political knowledge is $34.8 \%$ for the first category and $58 \%$ for the second category. The older students have less knowledge ranged from $5.8 \%$ to $1.4 \%$. Therefore, the level of the political knowledge is convex shaped. The older student is aware of less knowledge, but the younger student is aware of more knowledge. Overall, the age is inversely proportional to the level of knowledge for the Libyan university students. The results refer to the student in the recent academic grades have more information and political knowledge than those who are in late grades.

8 - Auouzo is a village on Chad - Libya borders that was a pivotal point in the Chad- Libya struggle. It is a part of Libya under the agreement between Italy, the colonizer of Libya, and France, the colonizer of Chad, that France abandons the border strip of Libya to Italy in 1935 . Its area is $80000 \mathrm{~km}^{2}$. For more see http://ar.wikipedia.org. 


\subsection{The Variable of the Place of Residence}

The results of the analysis show that there are few differences between the level of knowledge for the Jordanian University students according to the place of residence between those who live in cities and villages as they are laid down in the following table:

Table (3) shows the arithmetical overages, standard deviations and the test of the sample of study according to the variable of residence:

\begin{tabular}{|c|c|c|c|c|c|c|c|}
\hline Dimension & $\begin{array}{c}\text { Place of } \\
\text { Residence }\end{array}$ & Number & $\begin{array}{c}\text { Arithmetic } \\
\text { overage }\end{array}$ & $\begin{array}{l}\text { Standard } \\
\text { deviation }\end{array}$ & value & $\begin{array}{l}\text { Freedom } \\
\text { Degree }\end{array}$ & $\begin{array}{l}\text { Statistical } \\
\text { reference }\end{array}$ \\
\hline \multirow{2}{*}{$\begin{array}{c}\text { The level of the } \\
\text { political knowledge }\end{array}$} & Village & 40 & 12.38 & 3.18 & \multirow{2}{*}{0.983} & \multirow{2}{*}{99} & \multirow{2}{*}{0.326} \\
\hline & city & 61 & 11.72 & 3.31 & & & \\
\hline
\end{tabular}

The previous table shows that there is no difference of a statistical evidence at the level of the statistical significance $(\alpha=0.05)$. This result is sound to be natural at the period of opening the world and removing barriers. The principles of globalization prevailed and communication devices increased which resulted in a very close rapprochement between the city and village and providing most sources of knowledge in village as in city thanks to the technological progress, transport and communications (Al- Sharaa, 2014).

As per the Libyan students, the data shows that there are differences between the place of residence and the political knowledge. It shows that the students of cities are more aware of the political aspects than the villagers. The results of analysis show that the political knowledge for the students of cities is by $78.1 \%$ whereas for the villagers is low by $21.9 \%$.

The previous results show that the political knowledge of the rural students in the two communities of Jordan and Libya is less than those of cities. The results show a rapprochement between the Jordanian villagers and the residents of cities (Arcury Christianson, 1993) because the two communities are mostly rural. For the sample of the Libyan students, there are big differences between the level of knowledge for the resident of cities and the villagers. It is attributed to a number of reasons. According to the researcher's analysis, they include the huge area of the country, the large distance between the cities and villages, the lack of population who are scattered and the difference in the technological facilities which negatively affected on the level of the political knowledge of the sample (Romer, 2001).

\subsection{According to the Semesters}

The analysis of the sample shows a high level of knowledge according to the semesters. In the Libyan case, it is shown that there is a high level in the political knowledge with the high level of education. The results show that the students of advanced grades are more aware of the political knowledge about the recent years. The differences are clear because they show that the level of the political knowledge for the students of the advanced grades is by $40 \%$ whereas in the most recent grades "the first grade" it is by $20 \%$. The rest of proportions are distributed between the different grades. In the Libyan case, the results show an inverse relationship between the semesters and the political knowledge. The data shows that the level knowledge for the first grade is by $50 \%$ for the second grade by $44.1 \%$. It continues in its fall to $1.5 \%$ whereas it goes high again at the fourth grade by $4.4 \%$. It is different from the natural base that sees that the high level of the political knowledge with the student's educational high level. It requires conducting other studies of measurement to determine to what extent the results are valid. Also, it is attributed to the role played by the university in transferring the political knowledge, lack of specialists in politics during the last periods in the two universities, and lack of the quantity and quality of the political topics in the academic curricula (Mclaren, 1986).

\subsection{The Effect of the Level of Parental Education}

The results show that the level of parental education does not affect the proportional distribution of the sons' political knowledge. For the sample of the Jordanian students, the results show that the lower in education is more aware of knowledge and political skills. It is shown that the students whose parents of medium education are more aware of the political issues. Their percentage is $37.3 \%$. The political knowledge of the students whose parents are higher in their educational level (master and higher degrees) is lower than the medium level by $27.8 \%$. This result can be surprising at first sight because the expected thing is the opposite. It may be attributed to the nature of the profession of the parents (Sombat, 2010). In the Libyan case, the results of the sample show that the sons, whose level of the political knowledge is high by $68 \%$, have parents whose educational level does not exceed the primary certificate whereas the students whose political knowledge does not exceed $17 \%$ are of parents who are university certificate holders. It may be attributed to the fact that the father is preoccupied by 
making living and his daily routine. It is also for the lack of truth between parents and their sons in Arab Communities (Karima, 2011), the existence of barriers in most of the Libyan families and the control of the customs and traditions (Al- Mariami, 2008). It may be attributed to the fact that those who are lower academic qualification talk to their sons more. For example, if they work in a farm, they exercise their work with their families. It contrast, the holder of the higher qualification is less because he is mostly preoccupied and exercises his work individually (Al-Shara, 2014).

\subsection{The Degree of Correlation}

The results show that the historical knowledge is the most correlated in the indicator of information followed by the interest of the political topics and the ability to form a decision. The results of analysis show that the level of morale for (Jama) measurement for all the previous bilateral relations in the level of morale $(\alpha \geq 0.05)$. In other words, the proportional distribution for the indicator of the whole information of the student is not affected by independent changes and with a degree of consistency by $(0.634){ }^{9}$

\subsection{Exercising Politics for Students inside the University}

It is represented in the Union of students and its role inside the university. The sample of the Jordanian students sees that the union of students plays its role in medium level by $57 \%$ whereas $15 \%$ see that its role is not effective. $5 \%$ see that the union of students does not play any role.

\subsection{The Correlation of the University with the External Community}

According to the sample, the results show that the university community is correlated with the external community. The sample of the Jordanian students shows that the two communities are correlated by $75 \%$ whereas $8 \%$ of the sample sees that the correlation of the two communities is limited. As for the sample of the Libyan students shows that $65 \%$ think that are one community whereas $10 \%$ see that the correlation is limited. $15 \%$ think that there is no relationship.

\section{Conclusion}

6.1 The results refer to a high level of the internal knowledge of the two communities of the study. In indicates to the focus and interest in the internal political aspects "the interest in the internal matter". The Jordanian sample is different from the Libyan one due to the emergence of the result of the external political knowledge. It indicates to controlling and following the channels of transferring the political knowledge.

6.2 The results of the current study show that the level of the sample's political knowledge is medium for the two categories. The level of knowledge of the Jordanian university students is higher than that of the students of the Libyan university especially at the level of the knowledge of the political institutions, and the leaders and the political characters.

6.3 It is clear that the historical knowledge is the most correlated followed by the interest in political topics and the ability to form an opinion. Whereas the legal knowledge is the least correlated in the indicator of knowledge as a whole.

6.4 There is an inverse relationship between the results of the two cases of Jordan and Libya. The results of the Jordanian case show the high level of the political knowledge with the more advanced academic grade. There is an inverse relationship in the Libyan case between the academic grade and the level of the political knowledge. The results show a low level of knowledge with the more advanced academic grade of the examined student. This result indicates to the poor role of the university to teach its students political knowledge and awareness. Also, it indicates to a lack of the interest in the previous political systems by functioning the channels of transferring the political knowledge for youth which resulted in hollow young people of the content of the political knowledge (the report of Sky News Channel, 2016).

6.5 There is an inverse relationship between age and the level of students' political knowledge. In the Jordanian case, the result shows that there is a direct relationship between the high level of political knowledge and the old age. In contrary to the Libyan case, the less political knowledge is accompanied by the older age. That is because the university does not play its full role transferring political knowledge (Khashim, 2013). It may be attributed to the current events of Libya that lead to the lack of focus on the category of older youth for security circumstances. This aspect needs more research papers.

6.6 There are differences that have statistical indicators according to the variable of residence for the benefit of the residents of cities and not the villagers. The results show that there is a direct relationship between political

9 - The measure of Alpha Cronbach is used to measure the degree of consistency 
knowledge and the places of over crowdedness in the two cases of the study. It is attributed to the fact that the channels of transferring and gaining knowledge in cities are more than villages and rural areas. First and second, it is because the rural people are more preoccupied by fieldwork and crafts that need time and effort (Al- Kharif, 2001). Additionally, there are customs and traditions which control more in the villages of the Bedouin communities. That is why they are more closed and refused to the resources of gaining open political knowledge (the news network, 2015). The illiteracy rate increases because most of families are not interested in joining their children to schools in the rural areas for many factors. The most important of them are poverty, the lack of chances of education owing to the geographical extension and the separation of areas from each other which negatively affects the level of cognitive formation (Khashim, 2013).

6.7 There is no relationship between the educational level of parents and the level of political knowledge of sons. It proves the exclusion of an important aspect in increasing and establishing political knowledge. It is attributed to some factors: upbringing, transferring political knowledge adopted by most of Arab families, roughness of treatment making barriers in discussion between the members of family, no clarity, transparency or truthfulness. On the other hand, most of families are interested in social and scientific aspects but not the political ones. This result may be surprising at first sight. The opposite is expected. It may be attributed to the nature of the parents' professions especially father's (Jennings, 2009).

6.8 The level of political knowledge of Jordanian and Libyan university students in question is low. It increases in villages and rural areas especially basic political aspects that play a pivotal role in political participation and the right explanation of political events in a world where is no room for the weak person in all aspect especially cultural aspects. It needs a serious pause by the concerned bodies especially universities. It needs the state to intensify efforts to focus on political aspects in academic curricula by attention to means of transferring other knowledge to inform parents the importance of educating their sons' increasing political knowledge and investing the channels of transferring culture and political knowledge in a more precise and concentrating way especially that the two countries seek to form modern communities to be built on a sound democratic base (AlQamat, 2007).

\section{References}

Abdullah, S. K. (2012). The Globalization: The Degree of Awareness of the Students of the Applicable University of Al-Balqaa of the Concept of Political Culture and its Dimensions. Journal of the Studies of the Humanity Studies, 39(2), 325-346.

Al Abdali, S. (2007). Culture of Democracy in the Political Life of Yemen's Tribes. Beirut: Arab Unity Studies Center.

Al Hariri, A. A. (2011). The Role of Media in Forming the Political Culture of Libyan Youth: Libyan Visual Radio as A Case Study (Unpublished master's thesis). Benghazi: Post-Graduate Academy.

Al- Mashaqia, A. (2015). The Factors of Political Stability in the Kingdom, Jordan: The Opinion Newspaper. Retrieved from http://alrai.com/article/715773.html

Al- Masri, R. (2007). The Level of Political Awareness of the Members of the Movement of the Palestinian National Liberation. The Magazine of the University of Al-Aqsa, 11(2), 38-73.

Al- Nabolsi, H. (2010). The Role of University Youth in the Volunteering Work and the Youth Participation. Oman: Dar Al-Magdalawi for Distribution and Publication.

Al-Aghaa Abdel Atti. (2010). Al-Agha Resort, The Level of Political Knowledge of the Students of the Islamic University. The magazine of studies in curricula and methods of teaching, 139, 99-100. Retrieved from http://www.libya-al-mostakbal.org

Al-Marimi, O. A. (2008). Human Rights in Political Culture in Libya (Unpublished master's thesis). Benghazi: Faculty of Economics and Political Science.

Al-Momani, M. H. (2010). Political Attitude Among University Students in Jordan: A Statistical Field Study. University of Jordan of Studies, Human and Social Sciences Journal, 35(1), 137-149.

Al-Qamatti, G. (2007). The Reform in Libya and the lost conditions of its success Libya the Future. Retrieved from http://archive.libya-al-mostakbal.org

Al-Rashid, A. The Cultural Criticism for Political Culture. The informative network of news. Retrieved from http://annabaa.org.

Al-Sharaa, N. (January, 2014). The Degree of Political Knowledge of the Female Students of the Department of 
the Educational Sciences in the University Faculty of Arid, Asiut. The Magazine of the studies in the Higher Education, 155-179.

Al-Taiyeb, A. R. K. (2013). The Role of Family in the Directions of the Sons to the University Major from the University Point of View. A field study in the University of Qasedi Meryah (Unpublished master's thesis). Algeria: The University of Warqala.

Al-Taiyeb, M. (2001), The Political Upbringing and its Role in the Community Development. Oman: The Arab International Institution for Distribution.

Arcury, T. A., \& Christianson, E. H. (1993). Rural-urban Differences in Environmental Knowledge and Actions. The Journal of Environmental Education, 25(1), 19-25.

Autumn, R. (2001). The Characteristics of the Bedouin Community. The Journal of the Faculty of Humanities and Social Sciences, 24, 184-185.

Barakat, Z., \& Awad, A. (2010). The Role of Arab Universities in the Development of the Knowledge Society from the Point of View of a Sample of its Faculty Members. Journal of Attehad AlGameat AlArabia, 56, $75-110$

Bo Ali, N. S. (2014). The Use of University Youth in the Traditional and New Media: A Case Study. Journal of Al-Sharja, 2, 8-37.

Brion, F. (2016). The Historical Roots of the Libyan Question. Aragen Journal, 9, 1-6. Retrieved from http://www.libyaakhbar.com/libya-news/63041.html.

Capasso, M. (2013). Understanding Libya's Revolution through Transformation of the Jamahiriyya into a State of Exception. Middle East Critique, 22(2), 115-128.

Dimitrova, D. V., Shehata, A., Strömbäck, J., \& Nord, L. W. (2014). The Effects of Digital Media on Political Knowledge and Participation in Election Campaigns: Evidence from Panel Data. Communication Research, 1(41), 95-118.

Gabriel, A., \& Sidney, V. (1963). The Civic Culture: Political Attitudes and Democracy in Five Nation. Princeton: University Press.

Gabriel, A. (1990). A Discipline Divided: Schools and Sects in Political Science. London: Sage Publications.

General Education in Libya, the Bottlenecks, Challenges and Means of Treatment. Retrieved from, http://loopsresearch.org/media/images/photofmkdgao2jn,pdf

Giroux, H., \& McLaren, P. (1986). Teacher Education and the politics of Engagement: The Case for Democratic Schooling. Harvard Educational Review, 56(3), 213-239.

Horon, A. (2010). The Role of the University Formation in Upgrading the Scientific Knowledge (Unpublished master's thesis). Algeria: the Faculty of Humanity and Social Sciences.

Howk, J. C. (2008). Lions in the Path of Stability and Security Oman's Response to Pressing Issues in the Middle East (Unpublished doctoral dissertation). California: Naval Postgraduate School.

Jacobsen, D. I. (2001). Higher Education as an Arena for Political Socialization: Myth or Reality? Scandinavian Political Studies, 24(4), 351-369.

Jennings, M. (2009). Kent Political Socialization. In J. D. Russell \& D. K. Hans. (Eds.), The Oxford Hand Book of Political Behavior. New York: Oxford University Press.

Karima, K. (2011). The Dialogue between Fathers and Sons (Unpublished master's thesis). Algeria: The Faculty of Social Sciences.

Khalil, A. (2003). The Political Bequeathing in the Arab Republican Organizations. Beirut: the Arab Institution for Studies and Distribution.

Khashim, M. A. (2013). The Impact of Democratic Transitions on Political Culture in New Libya. Benghazi: Center for Political and Economic Research and Studies, Press Promotion and Support Authority.

Libya After Gaddafi: Many governments and Unknown Destiny. The Report Sky News Arabia (March, 2016). Retrieved from http://www.skynewsarabia.com

Maher, Q. M. (2010). The Increases of the Level of Political Knowledge of the Teachers of the Social Sciences in Jordan and its Relations to Some Changes. The Islamic University Journal, 18(2), 399-428.

Melod, G. (2013). The Role of the Scientific and Technological Programs in the Arab Satellite Channels in the 
Distribution of the Scientific Culture and Encouraging Creativity for the Libyan University Youth (Unpublished doctoral dissertation). Cairo: the Faculty of Mass Communications,

Mesto, M. (2013). The Controversial Discussions of the Political Parties in Libya Worthen the Situation of Security in Libya, Al-Hurra. Retrieved from https://www.alhurra.com/a/libya-controversial-betweenpolitical-parties-aggravate-security-situation/224506.html

Moawad, G. (1983). The Crisis of Political Participation in the Arab World. Lebanon: The Journal of the Arab Future, 6(55), 108-119.

Moussa, H. (2017). The Border Conflict between Libya and Chad on "Aouzou Sector" and the Peaceful Ways in the Settlement, Cairo, The Arab Democratic Center for the Strategic Political and Economic Studies. Retrieved from http://democraticac.de/?p=788

Nour Eddin, M., \& Mubarka, K. The Role of Parents in the Determination of the Future of their Sons at the Level of Guidelines. The Magazine of Humanity and Social Sciences, 24, 81-90.

Romer, N. ( 2001). Political Socialization. Retrieved from https://www.galloudeu / edu / depenna, plosoc

Shambash, A. M. (1996). Political Science. Misurata: The General Establishment for Publishing, Distribution \& Advertising.

Siddiq, H. (2012). Trends from a Sociological Perspective. Damascus University Journal, 28(3), 299-322.

The Center of Carter for Democracy. (2014). A Report on Elections, The Constituent Body for Phrasing the Constitution, issued by The General National Libyan Conference. Retrieved from https://www.cartercenter. $\mathrm{org} / \mathrm{resources} / \mathrm{pdfs} / \mathrm{news} /$ peace_publications/election_reports/libya-07302014-con-drafting-arabic-final.pdf

The Libyan Organization for Politics and Strategies, the Indicator of Libya. Retrieved from www.loopsresearch.org

The Report of the Team of the European Union to Evaluate Elections (July, 2012). the final report, the elections of the general national conference. Retrieved from https://www.cartercenter.org/.../election_reports/libya-070712-final-rpt-arabic.pdf

Zawati, H. M. (2016). M. Cherif Bassiouni (Ed.), Libya: From Repression to Revolution: A Record of Armed Conflict and International Law Violations, 2011-2013. Retrieved from www.ohchr.org/Documents/HRBodies/HRCouncil/.../Session19/A-HRC-19-68_ar.doc

\section{Copyrights}

Copyright for this article is retained by the author(s), with first publication rights granted to the journal.

This is an open-access article distributed under the terms and conditions of the Creative Commons Attribution license (http://creativecommons.org/licenses/by/4.0/). 